\title{
FORUM
}

\section{John Hamilton Moore and Nathaniel Bowditch}

\author{
Charles H. Cotter
}

JoHN Hamilton Moore (1738-1807), a well-known teacher of navigation, was born in Edinburgh, educated in Ireland, and subsequently joined the Royal Navy at Plymouth. In about $177^{\circ}$ Moore established a Nautical Academy in Brentford, Middlesex, and in 1772 he published his popular epitome of navigation under the title The New Practical Navigator and Daily Assistant. Later he established himself at 127 , Minories, near Tower Hill, where he not only taught navigation to 'Gentlemen designed for, or belonging to the sea' but carried on the business, aided by his sons and son-in-law Robert Blachford, of chart-seller and purveyor of nautical instruments. In the preface to the twelfth (1796) edition of his Practical Navigator, Moore presumed that he had been enabled to have made gradual but progressive improvements in navigation as his 'knowledge became extended through investigation' and as his 'judgement matured by experience'. In this edition of his work Moore styled himself as 'Teacher of Navigation, Hydrographer and Chart-seller to His Royal Highness the Duke of Clarence'. There can be no doubt that Moore's Practical Navigator was favourably received; and, indeed, a twentieth edition was brought out by Joseph F. Dessiou (17901842), a master in the Royal Navy who, on retiring from sea-service, was employed in the Admiralty Hydrographic Office where he specialized in the study of tides. Dessiou's twentieth edition of Moore appeared in 1828 , some $2 \mathrm{I}$ years after the death of its original author.

The late Professor E. G. R. Taylor' informs us that Moore had the 'flattering (if unrewarded) experience of having his book printed verbatim in the new United States of America'. The plagiarized version of Moore's Practical Navigator appeared under the name of Nathaniel Bowditch. The name Bowditch is wellknown among navigators the world over, and it has been since soon after the first American edition of Moore's book had been published in 1799. John Hamilton Moore's name, on the other hand, is almost forgotten.

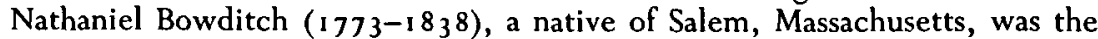
fourth child of Habakkuk Bowditch, a Salem ship master. Largely self-educated, Nathaniel became an expert mathematician and astronomer, whose most notable feat was perhaps the translation into English of Simon Laplace's Traité de Mécanique Céleste. Without detracting from the genius of Bowditch (who was undoubtedly an exceptional person) but to do justice to the memory of John Hamilton Moore, it is appropriate to consider the somewhat exaggerated claims that have been made from time to time on behalf of Bowditch in relation to the calumny suffered by Moore. How might Bowditch have taken the description of himself, for example, as: 'this genius who presented to the world the science of navigation as it is known today' ?2 And how might poor old Hamilton Moore have felt when it was claimed that Bowditch corrected: 'more than 8000 errors' found in the Practical Navigator? 3 
Bowditch was the editor of two editions of Moore's Practical Navigator in America, published respectively in 1799 and 1800 by Edward Blunt of Newburyport, Massachusetts. In 1802 Blunt published the first edition of Bowditch's The New American Practical Navigator which was a revision of Moore's original work. Admittedly Bowditch's revised version was a significant improvement on Moore's original ; many errors in tabulated quantities in Moore's book had been corrected and some of the original tables had been recomputed and errors eliminated. Perhaps Moore's table of maritime positions needed considerable attention; at that time the chronometer was fast becoming commonplace, and the longitudes of harbours, headlands and other navigational marks were now being found to an accuracy hitherto impossible.

It is interesting that an edition of Bowditch's book was published in England under the title The Improved Practical Navigator, ${ }^{4}$ edited by Thomas Kirby and sold by David Steel at his navigation warehouse in the Minories. Steel, it is to be noted, was Moore's fiercest competitor in the chart-selling business.

Kirby, who was employed by Steel as a teacher of navigation, informs us in the preface to The Improved Practical Navigator, that:

When it became necessary to print a third edition [of Moore's book], Mr. Bowditch, upon careful examination of that treatise, found the tables so erroneous, and the arrangement so faulty, that he resolved to take up the subject anew; and, without confining himself to Mr. Moore's work, to have recourse to those authors whose writings would afford the best materials for the purpose...

Perhaps to justify the English edition of Bowditch's revision of Moore, Kirby emphasized the defects of the latter's book; and, in the light of Kirby's remarks, Moore deserved to be censured for allowing errors to be repeated in edition after edition of his Practical Navigator.

The most complete treatise on navigation during the latter part of the eighteenth century was John Robertson's Elements of Navigation, a massive twovolume work containing numerous deomonstrations of navigational problems and theorems, designed specifically for the mathematical scholars of Christ's Hospital School, of which Robertson was mathematical master. Robertson's Elements complemented the Requisite Tables 5 by the Astronomer-Royal, Nevil Maskelyne-the two works together forming, at the time, a complete system of navigation.

Kirby pointed out that Robertson's work was useless to the generality of seamen 'who care but little for the demonstration of the rules they work by'. He then claimed that Moore, noticing this circumstance, resolved to form his work on a different plan: 'to contain only such matters as might be useful to the mere practical navigator'. Kirby alleged that Moore:

... copied most of the practical rules of Mr. Robertson, and the Tables of Dr. Maskelyne, and formed a treatise ... which has had a rapid sale; but rather from the principles of its construction than from the execution of the work ...

He further claimed that Moore's work was 'extremely faulty' and that Moore failed to 'correct any errors in the works he copied from'.

A large number of errors discovered by Bowditch in Moore's Practical Navigator appeared in the two extensive Traverse Tables, for points and degrees, 
respectively. A random check on a single page of the degree Traverse Table for $14^{\circ}$ reveals 27 discrepancies. Moore had reproduced Maskelyne's Table of Proportional Logarithms, and this also contained several errors which, like those in the Traverse Tables, were mostly in the decimal quantities. The tables of $\log$ trig functions also contained errors, and so did the table of amplitudes, although none of the errors in the amplitude table exceeded half-a-degree. The table of 'Latitudes and Longitudes' given in Bowditch's book was more extensive, and more accurate, than Moore's corresponding table, and Bowditch was cautious in remarking:

Notwithstanding the care taken in correcting the table, it must, from the nature of it, be in a degree erroneous, owing to the uncertainty of the observations on which it is founded...

To state that Moore's table contained more than 8000 errors might create the false impression that Moore was a charlatan and his book utterly worthless. The errors were mostly of a trivial nature and, to a large extent, were acceptable in the practice of navigation at the time. Moore's aim in producing the Practical Navigator was laudable: to provide a useful tool for the practical navigator, as opposed to the pupil or student of navigation. In the preface to the 1796 edition (that which was plagiarized by Bowditch and Blunt) Moore remarks:

I am well aware that there are persons who, to show their own superior abilities in an obscure club, will quibble and carp at some parts [of the book] and say, that they see nothing new. To such Critics it may be answered, that a Triangle was a Triangle before the days of Euclid, and so it is now ; but, if the arranging, digesting, simplifying, and rendering Navigation attainable to the most common capacity, with all the useful tables contained in one Book, which was never done before, it certainly may be called New, or at least an Improvement ...

In a brief 'Caution to Seamen' Moore remarked that persons in Scotland, Ireland, and other places, had copied his works and distributed them in different parts of the world:

... in order to prevent', he wrote, 'such spurious and erroneous Editions being imposed on the Public in future, a striking likeness of the Author, drawn by Muller, and engraved by Baker, will be prefixed to each book of this new [ 12 th] work.'

It is clear therefore that the plagiarism of printed works at that time was no uncommon thing.

Credit for having corrected the tabular errors in Moore's book rightly belongs to Nathaniel Bowditch, but the arrangement of the latter's book is essentially the same as that of Moore's; and, moreover, certain sections are identical in the two works.

Bowditch's fame stems primarily from the adoption of his American Practical Navigator by the United States Navy Hydrographic Office in 1868, when the copyright passed from Bowditch's son who had edited successive issues of the book after his father's death in 1838 . Familiarly known as 'Bowditch' but officially as 'H.O. Publication No. 9' the more recent issues are monuments to the skill, resources and industry of their respective editors. But part of Bowditch's fame rests on the shoulders of John Hamilton Moore whose New 
Practical Navigator, the British manual of navigation popular during Nelson's days, provided the firm foundation on which Bowditch was to build. Perhaps this brief note will help to restore Moore's damaged reputation.

\section{NOTES AND REFERENCES}

1 Taylor, E. G. R. (1966). The Mathematical Practitioners of Hanoverian England 17141840. Cambridge. See also Admiral Cramer's paper 'The military chartmaker' in the January 1977 issue of this Journal.

2 Anon. (1943). Americans who have Contributed to the History and Traditions of the United States Merchant Marine. Compiled and published by the Educational Unit of the U.S. Merchant Marine Cadet Corps.

3 Anon. (1966). H.O. Pub. No. 9. American Practical Navigator originally by Nathaniel Bowditch, LL.D. Washington, p. 4.

4 Kirby, T. (1803). The Improved Practical Navigator. Third Edition. London.

5 Maskelyne, N. (1767). Tables Requisite to be used with the Nautical Ephemeris. London. Second Edition, 1788; Third and last Edition, 1802.

\section{'The Military Chartmaker'}

\section{A. Harrison}

Vice admiral Shannon D. Cramer, Jr., presented the American contribution to the development of navigational charts in his paper (this Journal, 30, 15, Jan. 1977). He comments that:

It is seldom realized that the first flight across the Atlantic was completed by the U.S. Navy in 1919-eight years before Charles A. Lindbergh's courageous solo flight.

There are two points which appear to be equally seldom realized.

( 1) The U.S. Navy flight certainly crossed from one Atlantic coast to the other, but the crossing was achieved by one flight from Newfoundland to the Azores on 16 May, 1919 and a second flight from the Azores to Lisbon nine days later on May 28.

(2) The first non-stop transatlantic flight was in fact made eighteen days later by Capt. John William Alcock and Lt. Arthur Whitten-Brown, in a Rolls-Royce powered 'Vimy' aircraft of the Royal Flying Corps. The take-off from Newfoundland was on 14 June, 1919 and the flight ended abruptly next day in an Irish bog in Galway. Since the crew walked away from it, by the pilot's definition it was a good landing. A monument at London Heathrow airport commemorates their feat.

As Admiral Cramer says, eight years then elapsed before Charles A. Lindbergh made the first solo transatlantic flight. 